\title{
EL CAMPO INTELECTUAL COLOMBIANO \\ DE LA PRIMERA MITAD DEL SIGLO XX: ENTREVISTA A PAULA ANDREA MARÍN COLORADO
}

\author{
THE COLOMBIAN INTELLECTUAL FIELD \\ OF THE FIRST HALF OF THE 20TH CENTURY: \\ INTERVIEW WITH PAULA ANDREA MARÍN COLORADO
}

\author{
Juan Zapata \\ Université Lille 3 \\ juan.zapata@univ-lille.fr \\ Recibido: 04/12/2017 - Aceptado: 18/10/2018 \\ doi.org/10.17533/udea.lyl.n75a10
}

D aula Andrea Marín Colorado (Manizales, Colombia, 1980) es Doctora en LiP teratura (Universidad de Antioquia). Magíster en Literatura Hispanoamericana (Instituto Caro y Cuervo). Licenciada en Lingüística y Literatura (Universidad Distrital Francisco José de Caldas). Ha sido becaria del Ministerio de Cultura (Programa Nacional de Estímulos, 2015), de Colciencias (Programa Doctorados Nacionales, 2012; Programa de Estancias Posdoctorales, 2017) y del Instituto Caro y Cuervo (2005). Sus líneas de investigación son la historia literaria y la historia de la edición y de la lectura en Colombia. Ha sido docente e investigadora en instituciones de educación superior bogotanas durante los últimos once años. Es autora de más de una veintena de artículos, publicados en revistas académicas colombianas, argentinas, chilenas y españolas. Es autora, además, de casi una decena de capítulos de libros de investigación y de los libros Acercamiento a la novela colombiana de los setenta: Los parientes de Ester de Luis Fayad y Juegos de mentes de Carlos Perozzo. Aproximación sociocrítica (Instituto Caro y Cuervo, 2010), De la abyección a la revuelta: La nueva novela colombiana de Evelio Rosero, Tomás González y Antonio Ungar (Pontificia Universidad Javeriana, 2013), Novela, autonomía y profesionalización del escritor en Colombia (1926-1970) (Universidad de Antioquia-La Carreta Editores E.U., 2017), y Un momento en la historia de la edición y de la lectura en

Colombia (1925-1954). Germán Arciniegas y Arturo Zapata. Dos editores y sus proyectos (Editorial Universidad del Rosario, 2017). En la actualidad, Paula Andrea se desempeña como coordinadora de la Maestría en Estudios Editoriales del Instituto Caro y Cuervo y como directora de la línea de investigación El Libro en Colombia. Además, coordina el nodo Colombia para el proyecto internacional Editores y Edi- 
toriales Iberoamericanos (siglos XIX-XXI)-EDI-RED y es miembro de los grupos de investigación: Colombia: tradiciones de la palabra (Universidad de Antioquia) y Grupo de Investigaciones en Literatura del Instituto Caro y Cuervo.

Esta entrevista fue realizada a propósito de la publicación de su libro Novela, autonomía literaria y profesionalización del escritor en Colombia (1926-1970) (Marín, 2017) e hizo parte de la programación de las Jornadas Académicas organizadas por el grupo de investigación Colombia: tradiciones de la palabra (Medellín, Universidad de Antioquia, 9-10 de noviembre de 2017). El aporte del libro de Paula Andrea Marín a los estudios literarios en Colombia radica en las dimensiones de su corpus y en el alcance de su propuesta metodológica. Al aplicar un análisis de corte social e histórico, la investigadora logra describir con precisión los mecanismos que gobiernan la escena literaria de las tres primeras partes del siglo XX y el papel que jugaron los novelistas, pero también los críticos y demás instancias de difusión y consagración, en la institucionalización de la autonomía literaria en Colombia. Pero el alcance de su investigación no se queda ahí. Al confrontar estas nuevas propuestas teóricas y metodológicas con el corpus de la literatura colombiana, la investigadora pone a prueba dichas propuestas y las enriquece, obligándonos a reconsiderarlas a la luz de nuestro contexto colombiano.

Juan Zapata: Quisiera empezar esta conversación volviendo sobre una cuestión teórica que me parece esencial para comprender tu propuesta. Se trata de la diferenciación que estableces entre autonomía estética, autonomía intelectual y autonomía institucional. Si bien es cierto que estos tres aspectos se encuentran indisolublemente ligados en los procesos que describes, surge en tu investigación la necesidad de diferenciarlos a nivel teórico, para poder así describir con mayor claridad dichos procesos. ¿Podrías explicarnos dicha división y cómo esta nos ayuda a comprender mejor las prácticas que describes?

Paula Marín: Efectivamente, parto del concepto de autonomía, que es propuesto por Bourdieu, y tuve la necesidad de dividir ese concepto en tres subcategorías, que son la autonomía estética, la autonomía intelectual y la autonomía institucional, por cuestiones de metodología y para facilitar el análisis literario. Cuando leí Las reglas del arte y toda la propuesta de Bourdieu, me di cuenta de que él definía autonomía a través de diversos elementos, y que esos elementos, para hacer más fácil el análisis, podían agruparse en las tres categorías que acabé de mencionar.

La autonomía estética tiene que ver con el grado de "artepurismo", que se puede encontrar en ciertas propuestas literarias, es decir, aquellas donde lo formal o la experimentación son mucho más importantes que la representación literaria "realista". Por su parte, la autonomía intelectual se relaciona con el grado de independencia, de libertad que tiene el autor para enunciar su palabra y su letra para actuar en el 
campo literario, así como la posibilidad de sustraerse a los poderes dominantes, provenientes, por lo general, del campo político, religioso y económico; es entonces la posibilidad que tiene un escritor de instalarse en un lugar de enunciación en donde pueda hablar de cualquier tema y en los términos que decida. Por último, está la autonomía institucional, que está relacionada con la base material de la literatura y la vida literaria: las instancias de legitimación de lo literario, el mercado editorial, el público lector, los premios, el estado del proceso de profesionalización del escritor - la posibilidad de que derive sus ingresos de actividades más cercanas al campo de las letras - así como de todos los agentes del campo literario y, en general, todas las formas de valorización de lo literario, de cómo se legitima lo literario en un momento y en una sociedad determinada.

Este proceso de profesionalización del escritor va a ser fundamental en todo el proceso de mi investigación, puesto que, ciertamente, si nos remontamos al siglo XIX, y todavía en las primeras décadas del siglo XX, el escritor está muy alejado de lo que hoy podríamos denominar un campo de las letras. El escritor estaba más cercano al campo político y obviamente al campo periodístico, que era muy cercano al primero, pero con el paso del tiempo se hizo cada vez más fácil para él estar ubicado realmente en un campo que pudiéramos denominar literario.

Si se dan cuenta, son elementos muy diversos. Entonces, hablar de autonomía como un concepto general era más difícil que organizar este concepto a través de las tres categorías mencionadas.

¿Por qué el concepto de autonomía es tan importante en esta investigación? Porque Bourdieu define el campo literario a través de la institucionalización de la autonomía. Entonces, la autonomía o, mejor, los grados de autonomía sobre los que funciona el conjunto de actividades literarias, me permitían establecer desde qué momento - que era la pregunta esencial para mi investigación_-, podemos hablar del campo literario en Colombia y cuáles eran las particularidades del funcionamiento de dicha autonomía en él.

- Sin embargo, aunque se trate de una división metodológica, como tú lo explicabas, parece también que esta corresponde a diferentes periodos de esa búsqueda por la autonomía en el campo literario colombiano; lo que me lleva a la siguiente pregunta: ¿Los diferentes tipos de autonomía de los que tú hablas (la autonomía estética, la autonomía intelectual y la autonomía institucional) se dieron conjunta o sucesivamente? ¿Un tipo de autonomía predominaba sobre el otro en los diferentes períodos que describes?

-Bueno, la autonomía, su búsqueda y la creencia de los escritores en ella —que es como realmente Bourdieu la define_-, siempre ha acompañado a los fenómenos 
literarios y nunca se ha dado de forma plena, sino que siempre ha sido relativa; cada momento de la historia literaria está asociado a una forma particular, en la que los escritores pueden ejercer su autonomía frente a los poderes dominantes, no solo aquellos que funcionan fuera del campo literario, sino también en su interior. En otras palabras, si bien es cierto que no podamos hablar del campo literario en los términos que propone Bourdieu — porque no hay una institucionalización de esa autonomíaesta ha acompañado siempre los procesos literarios y la definición misma de autor.

En este sentido, los diferentes tipos de autonomía están presentes en la vida literaria, pero las transformaciones de la sociedad y de la vida literaria hacen que cada tipo de autonomía aumente o disminuya, en relación con los demás. En Colombia, específicamente, descubrí que la autonomía intelectual funcionaba como una especie de aguijoneador de los otros dos tipos de autonomía - quizá también en los otros campos nacionales funcione así, sobre todo, en los latinoamericanos y, en general, en los países "periféricos" - . El campo literario estaba muy cerca del campo político, porque no había aún una avanzada especialización de los subcampos del campo intelectual (político, literario, académico y periodístico), que solo se concretaría a mediados del siglo XX. De esta manera, los escritores que pertenecían o querían hacer parte activa de la vida intelectual del país tenían que militar en alguno de los partidos políticos (ser liberales o conservadores), sobre todo si querían trabajar para el Estado, que era lo más común en la época, pues constituía la forma más efectiva que tenía el escritor para acceder a "vitrinas" tan importantes de la vida literaria como la prensa y las redes de sociabilidad, que se creaban alrededor de los cafés, las editoriales, las imprentas, las librerías y las tertulias privadas.

Al hacer parte de la vida política y del ejercicio político, los escritores no tenían mucha posibilidad de enunciar un pensamiento independiente de los partidos políticos oficiales. En este sentido, la primera gran lucha de estos escritores para poder institucionalizar la autonomía con la que funciona el campo literario era la lucha por la independencia intelectual o por la autonomía intelectual, es decir, por la posibilidad de encontrar de nuevo un lugar de enunciación, en el que ellos pudieran hablar de lo que quisieran en los términos que quisieran, justificando la libertad de expresión en la potestad del arte y de la literatura. Si el escritor siente que puede hablar de la manera que prefiera, es más probable que las formas literarias que cree sean también más libres, más independientes del academicismo, del tradicionalismo literario y del arte más oficial. Asimismo, alrededor de la libertad de decir y de la autoridad del escritor se van creando unas formas más especializadas de circulación de lo literario, a través de mediadores, soportes y modos de legitimación que ratifican el poder simbólico del autor, y por ende, el de la literatura. 
Empecé el libro con los Nuevos a principios del siglo XX; a ellos los conocemos como un movimiento literario, pero cuando uno lee su revista (Los Nuevos) se da cuenta de que tenían un proyecto político detrás. Ellos eran funcionarios públicos que estaban adheridos al Partido Liberal, y por eso la revista mostraba un claro proyecto político de estos intelectuales y escritores de modernizar el Partido Liberal y, al mismo tiempo, para transformar la concepción del arte, de la literatura y del escritor en Colombia. Así, a partir de esa simbiosis entre política y literatura, por la cual funcionaba la vida literaria del país, los escritores buscaron plantear ideas diferentes y críticas frente a los partidos políticos oficiales y al arte más tradicional o academicista.

El segundo momento de configuración del campo literario, según mi investigación, tiene que ver con una mayor concreción de la afirmación que hice antes sobre la autonomía intelectual; allí tenemos los casos de dos escritores: Jaime Ardila Casamitjana y Jorge Zalamea Borda. Zalamea representó el punto más alto de mi afirmación, pues, al final de su trayectoria intelectual, por un lado, renunció al Partido Liberal para acercarse al socialismo y, por otro, le dio forma escrita a lo que él denomina "arte testimonial", una síntesis entre un arte que no le daba la espalda a la realidad, pero que afirmaba la autonomía estética como credo. Además, en esta etapa de su trayectoria y por obvias razones, Zalamea no ocupó cargos oficiales y se dedicó a ser profesor universitario, traductor, periodista y conferencista en diferentes ciudades del país, es decir, actividades más relacionadas con un campo propiamente literario.

El último capítulo del libro está dedicado a Gabriel García Márquez y a Alba Lucía Ángel, porque estas dos figuras me permitieron entender que para la época en la que empezaron a producir y legitimar sus obras podíamos hablar ya de un campo específicamente literario. Gabriel García Márquez no perteneció a ningún partido político oficial en Colombia ni ocupó cargos públicos, sino que eligió dedicar su vida a la escritura periodística y literaria. Su obra literaria fue legitimada en Colombia por los más prestigiosos críticos literarios del momento, como una obra en la que la autonomía estética no cedía terreno a lo político, lo comercial o lo tradicionalista. Por su parte, el caso de Alba Lucía Ángel es muy interesante, porque en ella aparece un discurso radical en contra de los lectores que buscan historias "fáciles" y también del campo económico, que deseaba convertir la literatura en pura mercancía. Por supuesto, Ángel ya estaba radicalmente separada del campo político.

Cuando comencé la investigación, pensaba que los tres tipos de autonomía debían darse al mismo tiempo, y que podíamos exigirles a los escritores que hicieran al mismo tiempo las rupturas estéticas e ideológicas, así como la institucionalización de la vida literaria y la profesionalización de su oficio. Pero gracias al libro de Beatriz 
Sarlo (1988), Una modernidad periférica, entendí que las rupturas estéticas a veces no se dan al mismo tiempo que las rupturas ideológicas o institucionales. Encontré obras literarias que parecen ser muy conservadoras o muy tradicionales en sus formas literarias, pero que plantean pensamientos sobre temas diferentes, novedosos y críticos para la época, sin que eso implicara una ruptura estética radical o el cambio absoluto de las formas estéticas tradicionales. Me di cuenta de que eso era lo que podía ver en los escritores colombianos: la lucha por poder decir y hacer lo que ellos realmente querían de la literatura posibilitó, más fácilmente en un momento posterior, que se diera una mayor cantidad de rupturas estéticas. Es decir, en la década de 1960 empezaron a aparecer muchas novelas y obras literarias en las que es posible identificar una mayor experimentación formal y más formas vanguardistas que las originadas en las décadas anteriores.

Como ustedes saben, una de las ideas concebidas sobre la literatura colombiana es que nosotros no tuvimos vanguardias. Lo que estoy diciendo explica, en parte, por qué nosotros no tuvimos vanguardias comparables a las que tuvieron otros países latinoamericanos.

La búsqueda de la autonomía intelectual tenía que hacerse para que los escritores tuvieran un mayor espacio de experimentación estética. Lo que estaban haciendo esas luchas era propender por una separación entre el campo literario y el campo político, y por la posibilidad de que la literatura fuera valorada solo teniendo en cuenta criterios estéticos, y no morales o políticos. Al propender por esa separación, se configura el campo literario, como plantea Bourdieu, con unas reglas propias de funcionamiento en las que lo importante es el valor simbólico o la creencia en el valor simbólico de la literatura.

-De ahí que hayas dividido tu investigación en tres momentos que dan cuenta de ese proceso de la autonomización de las prácticas literarias en Colombia. Un primer momento de ruptura es que iría desde los años veinte hasta los años cuarenta; un segundo momento es en el que se consolidó esa ruptura, que iría desde los años cuarenta hasta mediados de los cincuenta; y un tercer momento es en el que ya podemos hablar de la emergencia de un mercado editorial y una mayor institucionalización de las prácticas literarias, que iría desde finales de los años cincuenta hasta los años setenta. Quisiera que volviéramos a esas dos primeras partes, antes de centrarnos en la última parte que es, tal vez, en donde podemos hablar más claramente de la autonomización de la literatura. Y es que al leer los resultados de tu investigación, nos queda la impresión de que estamos frente a un momento del campo literario colombiano bastante paradójico. La frágil institucionalización de las prácticas literarias en aquel momento, cuya dependencia estructural de los campos político y religioso impedía su autonomización, así como la poca especialización de 
los productores culturales, que dependían aún del sistema de retribución oficial para su inserción social y económica, nos hace pensar que en dicho periodo, más que de la historia de la autonomización del campo literario, se trata más bien de la historia de los nuevos pensadores liberales, que querían arrebatarle su posición dominante a la hegemonía política y literaria de los conservadores.

- Sí, pero no serían dos procesos distintos. Es decir, sin la lucha de los pensadores liberales (en los dos primeros momentos que analicé en el libro, los intelectuales que estudio eran liberales) por arrebatarle esa hegemonía ideológica y estética a los conservadores (estamos hablando de la tercera década del siglo XX en Colombia, del paso hacia la República Liberal y luego hacia la "Restauración Conservadora" y el Frente Nacional), no hubiéramos podido tener la ganancia del grado de autonomía con el que funciona el campo intelectual en Colombia. Reitero la importancia del trabajo que hicieron los Nuevos. En el libro, trabajé los casos de José Restrepo Jaramillo y de Eduardo Zalamea Borda en aquel primer momento. Los dos trabajaron para el gobierno colombiano; a pesar de ser funcionarios públicos, hicieron una crítica frente al funcionamiento del Partido Liberal, de la política en Colombia y, a través de sus obras literarias, específicamente, hacen una crítica a cómo se escribía literatura en Colombia.

Es el caso, por ejemplo, de Eduardo Zalamea con Cuatro años a bordo de mí mismo, que es una novela ya muy canónica, pero que fue una de las primeras novelas que empezó a problematizar la moral establecida en Colombia. Algunas autoridades literarias — provenientes de la Academia Colombiana de la Lengua - la trataron de pornográfica cuando fue publicada, pero la crítica de la prensa, en general, la apoyó. ¿Por qué pornográfica? Porque Zalamea describía cuerpos desnudos y escenas sexuales. Lo que Zalamea pretendía demostrar era que las palabras no debían tener un peso moral, es decir, que las palabras no tienen un peso moral por sí mismas, y que cuando entran en el texto literario la palabra adquiere otro sentido, un sentido autónomo — eso lo sabemos todos los que estudiamos literatura-. Y eso era lo que estaba tratando de enunciar Zalamea Borda: no tratar la desnudez que aparecía en su libro como era tratada afuera, desde los preceptos moralistas establecidos; estaba proponiendo otro tipo de moral o, mejor, una ética y una estética "moderna".

Por su parte, el escritor José Restrepo Jaramillo defendía el poder del lenguaje literario, al propender en la Novela de los tres — para mí, la primera novela metaficcional que se publicó en la historia de la literatura colombiana- que funcionara como un verdadero artefacto literario, pues se sostiene por sí misma al no necesitar una relación directa con la realidad para significarse. Esa metaficción que está ahí presente propone que el lenguaje literario existe por sí mismo, y no para hacer pro- 
selitismo político, ni para entretener a los que él llamaba "lectores brutos", ni mucho menos para complacer la moral de los que él denominaba los "lectores de aldea".

En estas dos obras se critica el pensamiento oficial: el liberalismo y el conservatismo, las dos ideologías políticas que siempre acompañaron los procesos sociales y culturales en la primera mitad del siglo XX. Eso se acentuaría mucho más tras los hechos del 9 de abril de 1948 y la dictadura de Rojas Pinilla; lo que se puede apreciar, después de estos dos hechos históricos, son escritores que ya no están afiliados a ninguno de los dos partidos políticos oficiales. Se trata de un cisma que divide a los intelectuales colombianos, que los separó completamente de la política oficial del país y que los instaló definitivamente en un lugar de enunciación propiamente literario que, al mismo tiempo, les dio la libertad de decir y de hacer, de ser críticos frente a la realidad del país y de elaborar sus obras de la manera en que lo prefirieran.

-En ese sentido, los escritores que mencionas demostrarían que la autonomía intelectual conduce, como lo has afirmado, a una autonomía estética, que privilegia la forma sobre el contenido. Basándome en un sugestivo planteamiento tuyo y en casos similares que podemos encontrar en la literatura francesa, como el caso de los procesos judiciales que llevaron a Baudelaire y a Flaubert a comparecer en 1857 frente a la justicia del Segundo Imperio por ultraje a la moral pública, pensaría más bien que, en el periodo que describes (en el cual el establecimiento político y literario conservador ejercía una dominación prácticamente absoluta sobre las prácticas literarias, excluyendo del sistema de retribución económica y simbólica a aquellos nuevos pretendientes que no se sometían al principio de moralización en el arte), la defensa de una autonomía se jugaba menos en el credo modernista de la forma pura y más en las reivindicaciones del escritor para poder decirlo todo, para confrontarse con la realidad social más inmediata, realidad que los oficiantes conservadores del campo literario habían pretendido ocultar.

- Sí, totalmente de acuerdo. Esa sería, creo, una particularidad de la historia literaria colombiana y asumo que también de la latinoamericana. Nuestros escritores participaron activamente en la política y eso marca el tipo de autonomía que caracteriza nuestros campos literarios. Sin embargo, las reivindicaciones del escritor para poder decirlo todo conllevaban la búsqueda de una forma literaria que no fuera ni política ni moralista, y es esa búsqueda la que lo llevó a privilegiar —o, mejor, a legitimar-, de cierta manera y paulatinamente, la forma de representación sobre el objeto representado; entonces, la autonomía intelectual, tal como la entiendo, conduce al aumento de la autonomía estética.

—YY qué sería entonces lo que permite que pasemos ya a una autonomía institucional? 
- La autonomía institucional se define por la existencia de un mercado editorial, de un público lector más o menos amplio, la existencia de premios literarios y por la especialización del campo intelectual, que permite tener instancias de legitimación —entre ellas, las revistas —, a su vez, más especializadas; esa especialización del campo intelectual permite que el escritor pueda vivir de actividades cada vez más directamente derivadas del ejercicio literario (docencia en programas de formación literaria, bibliotecas, editoriales, traducciones, centros deinvestigación).Por ejemplo, en 1968, pasamos de tener un departamento que concentraba toda la actividad artística del país dentro del Ministerio de Educación, a la creación del Instituto Colombiano de Cultura (Colcultura), que se mantuvo hasta 1997, cuando se crea el Ministerio de Cultura; eso ya nos habla de una mayor especialización de ese campo artístico, y específicamente literario.

El sistema editorial colombiano, siempre ha sido muy precario, es decir, hasta hoy podemos decir que todavía estamos luchando por tener realmente un mercado editorial, por tener realmente un público lector para la producción editorial nacional. En los años sesenta, empezaron a surgir cada vez más proyectos editoriales. Más adelante, en los años setenta setenta, por ejemplo, se transformaron las cantidades de importación y exportación de libros colombianos, hubo cada vez más publicaciones de autores colombianos y menos importaciones de libros extranjeros. Pero antes, entre finales de los cuarenta y finales de los cincuenta sucedieron también dos hechos importantes: la instauración de una nueva ley de propiedad intelectual (1946) y de la primera ley del libro en Colombia (1958). Eso nos habla de la consolidación de un mercado editorial.

En cuanto a los premios, un referente muy importante para mi investigación fue la creación del Premio Esso de Novela. Dicho premio, a mi modo de ver, divide radicalmente las críticas provenientes tanto de la Academia de la Lengua como de la prensa. Lo que quiero decir es que a partir de ese premio y de las discusiones que sobre el mismo se generaron en la prensa del momento, se instauró como una regla general de funcionamiento del campo literario colombiano que la Academia de la Lengua ya no resultaba una instancia válida para evaluar las obras literarias; los escritores y la prensa se unieron para expresar que ya no necesitaban del concepto de la Academia de la Lengua, y que las obras se valorasen por criterios mucho más autónomos y acordes con la transformación que se estaba viviendo en el campo literario, en cuanto a la afirmación de nuevos valores estéticos.

Todo este conjunto de situaciones hace que podamos hablar de un grado de autonomía institucional mucho más alto que en las décadas anteriores, y es allí donde ubico, realmente $-\mathrm{y}$ tal vez esta es de las afirmaciones más problemáticas 
que pueda tener el libro-, el surgimiento del campo literario, porque antes sólo podíamos hablar de un campo intelectual.

- Sí, y estoy de acuerdo contigo en esa afirmación. Sin embargo, pienso que el campo literario o la autonomía del campo literario surgió a partir del momento en el que se hizo una división entre una esfera de producción restringida y una esfera de gran producción, y eso parece ocurrir en el momento que tú analizas en la tercera parte; es decir, el mercado editorial y la frágil industria editorial colombiana empezaron a tomar un poco más de fuerza, gracias a la masificación del público lector. Esto conllevaría a que el escritor se viera por primera vez confrontado, como tú misma lo señalas, con el mercado. Háblanos un poco más de esa confrontación, pues es allí cuando se afirma con mayor fuerza, a mi parecer, el credo de la autonomía de campo literario.

-Esa es una de las debilidades del libro, porque no tenemos investigaciones sobre la configuración del campo de gran producción en Colombia, de la literatura más "comercial" y "heterónoma". El grupo de investigación Colombia: Tradiciones de la Palabra (Universidad de Antioquia), en cabeza de Ana María Agudelo, ha emprendido investigaciones sobre la circulación de lo que podríamos denominar publicaciones periódicas populares; yo misma he adelantado algo al respecto con el estudio del caso del escritor pereirano Arturo Suárez, pero, por ahora, no hay nada más - al menos que yo conozca-. Como no tenemos mucha información acerca de la configuración del campo de gran producción, es difícil determinar hasta qué punto podemos decir que hay un surgimiento o un verdadero enfrentamiento de estos dos subcampos. Pero es un hecho que en los años sesenta y setenta empezaron a aumentar visiblemente las opiniones de los escritores y de la prensa acerca del valor económico asociado a la literatura como algo demonizado. En frases como "yo no escribo para vender" o "yo escribo para pocos lectores" se puede apreciar la fuerza que empezó a cobrar el mercado editorial nacional y, por supuesto, el aumento de la masa lectora, gracias al disparo en el aumento de la cobertura escolar y de las tasas de alfabetización, las cuales, hasta mediados del siglo XX, llegaban apenas al 40\%.

- ¿Y qué pasa entonces con el modernismo, que instauró la división entre el valor económico y simbólico de la literatura, división que radicalizó la distinción entre la esfera de producción restringida y la de gran producción? Ese credo ya existía, ¿no es así?

- Recuerden que el modernismo en Colombia — en concreto - tiene dos vertientes: una más "secularizada", en donde podemos ubicar a autores como Silva (y a los autores más representativos del modernismo latinoamericano) y — con todas las reservas del caso- a Vargas Vila; y otra mucho menos "secularizada", que es la 
que verdaderamente se consagra en Colombia: Rivas Groot y, sobre todo, Guillermo Valencia, quien estuvo más cercano al parnasianismo que al modernismo, pero que se declaró en este punto como el gran poeta modernista, quien se consagró como el escritor por antonomasia en Colombia y cuyo "imperio literario" duró hasta casi mediados del siglo XX, cuando aparecieron los piedracielistas y surgió una gran pugna en la prensa de la época, porque Eduardo Carranza dijo: «Ya no más Guillermo Valencia, ya no necesitamos más latín, ya no necesitamos más columnas griegas, ya no necesitamos más figuras exóticas en los poemas».

Me parece que esa es una de las características del campo literario colombiano: la ruptura causada por el modernismo no fue tan fuerte como lo fue en otras tradiciones literarias del continente; nuestros casos de poetas modernistas y vanguardistas fueron casos más aislados que de un movimiento continuo y consolidado. Una de las causas de este hecho sería también política $-\mathrm{y}$ allí vemos, de nuevo, la simbiosis entre política y literatura-. Encontré en mi investigación que los escritores defensores de ideas modernistas o vanguardistas eran inmediatamente identificados como "de izquierda", pero pocos de ellos querían ser señalados como tales, pues las tendencias comunistas o socialistas en Colombia — como lo sabemos - siempre han sido fatalmente perseguidas, excluidas y marginadas.

Lo anterior nos hace repensar realmente cómo podían ser las dinámicas tanto dentro del campo de producción restringida como en el de gran producción hacia inicios del siglo XX en Colombia. Pero, reitero, nos faltan investigaciones acerca de las relaciones entre estos dos subcampos.

-Esa es una idea muy sugestiva en tu libro. Tú me hiciste entender cómo el establecimiento político y literario conservador se apropió de ciertas tendencias modernistas y las adaptó a la estética de tipo humanista. Algo similar ocurrió en Francia con los parnasianos - Leconte de Lisle a la cabeza - quienes readaptaron el credo del arte por el arte a los principios del humanismo clásico. ¿Podrías explicarnos cómo hizo el establecimiento político y literario conservador para apropiarse e institucionalizar el credo poético del arte puro, credo que en sus inicios "modernistas" constituía la base de una reivindicación de la autonomía literaria? ¿Cómo convivía dicho credo con las tendencias regionalistas y costumbristas que defendían los conservadores en el arte?

- Creo que son tendencias distintas en Colombia: el modernismo, el parnasianismo y el humanismo clásico, pero, efectivamente, como tú dices, el establecimiento político y literario conservador reelaboró — para su beneficio - la idea del arte por el arte, aunque esta no era reciente — es decir, no era propia del modernismo-, sino que ya tenía un desarrollo desde la estética dieciochesca o neoclasicista. 
La tendencia del humanismo clásico de corte hispánico data, obviamente, del siglo XVIII, pero en el siglo XIX se siguió desarrollando en Colombia y fue adoptada, sobre todo, por Miguel Antonio Caro, Rafael Núñez y Rufino José Cuervo durante la Regeneración, y permaneció vigente en toda la primera mitad del siglo XX, gracias al trabajo de Marco Fidel Suárez y del padre Carrasquilla, entre otros. Parece increíble, pero en la investigación, luego de rastrear la prensa, los manuales de literatura y las historias de la literatura colombiana, me di cuenta de que, efectivamente, es un precepto literario que llega hasta mediados del siglo XX. Esto es tan cierto que el padre Félix Restrepo, director de la Academia Colombiana de la Lengua, en una entrevista que le hicieron en los sesenta, todavía mencionaba la vigencia del credo humanista clásico de corte hispánico.

Dicho humanismo clásico fue reelaborado, pues, durante la Regeneración, el cual estaba relacionado con el Imperio romano, con la iglesia católica y con España como la "Madre Patria". Para Miguel Antonio Caro, el Imperio romano todavía seguía vigente en cuanto a la noción de que las élites eran las que debían gobernar, la religión católica era la única válida y nuestro castellano debía tratar de apegarse más a la norma española. Además de lo anterior, estaban los preceptos artísticos del neoclasicismo dieciochesco: lo bueno, lo bello y lo verdadero. Dichos preceptos hacían que el artista tuviera solamente un abanico de temas para escoger como material de sus obras, porque eran los únicos "dignos" de ser tratados artísticamente, y que ese tratamiento estuviera supeditado a no representar los aspectos "bajos" de la sociedad, a riesgo de caer en la inmoralidad. La función de la literatura, en este contexto, quedaba así tácitamente relacionada con una función didáctica y de defensa del patriotismo. De allí que la estética costumbrista y regionalista de tintes folclóricos —o las obras leídas desde esta perspectiva - fue también, en cierto modo, asimilada por la estética del humanismo clásico. Por supuesto, esto quería decir que la literatura velaba la realidad, porque no podía mostrarla críticamente.

En este marco, el parnasianismo de Guillermo Valencia - leído en Colombia como sinónimo de modernismo- estaba directamente relacionado con ese humanismo clásico, que era defendido en Colombia por la tendencia artística y literaria más academicista, y por ello podemos entender su unánime aceptación por parte de las autoridades literarias más academicistas, tradicionalistas y "modernistas" hasta la aparición de los piedracielistas. El parnasianismo, al igual que el humanismo clásico y el modernismo defienden la idea de un arte puro, del arte por el arte y de un arte no utilitarista. Pero, la idea del humanismo clásico viene de la diferenciación entre los trabajos intelectuales y los trabajos manuales. Entre los siglos XVIII y XIX, solo podían escribir los que tenían rentas, aquellos que no tenían que trabajar con sus manos, porque eran quienes tenían tiempo para escribir y la educación necesaria para 
hacerlo; era muy clara la diferencia social entre quien podía dedicarse a las bellas artes o a las bellas letras y el que tenía que trabajar con sus manos para sobrevivir. Dicha creencia en la inutilidad del arte proviene de ahí, de esa diferenciación social en Colombia.

La idea del modernismo del arte por el arte es diferente y provino de algo más secular, de la renuncia a todo compromiso político, didáctico, moral, religioso o económico en el momento de crear la obra de arte.

-En el caso de los parnasianos y del humanismo clásico, se le dio la espalda al presente, proclamando así un tipo de atemporalidad y de ahistoricismo en el arte y la literatura. Tú mostraste muy bien en tu estudio cómo la novela de la violencia en Colombia empezó a representar aquello que no podía ser representado dentro de los cánones de la estética humanista clásica: la realidad política y social del país. En ese sentido — y esto me parece esencial en tu análisis — la novela comprometida socialmente contribuye también a la autonomización.

- Sí. Suena paradójico, pero es así. La novela de la violencia —en su primera fase de producción - o la novela socialmente comprometida defendió un tipo de autonomía: la de poder hablar crítica y libremente de la realidad; y la libertad para hablar de la realidad creó una estética particular que liberó, a su vez, las formas literarias tradicionales. Asimismo, la novela de la violencia conectó inmediatamente con un público lector que estaba ávido por que los escritores pusieran por escrito lo que estaba pasando a su alrededor, es decir, la novela de la violencia contribuyó a ampliar y a afianzar el público lector colombiano y el mercado editorial nacional.

Creo que la otra contribución teórica de esta investigación es analizar la autonomía estética desde otros puntos de vista, tanto desde la del productor, como la del autor mismo, y no solo desde los presupuestos teóricos, ni desde nuestros propios prejuicios como investigadores ni mucho menos desde los juicios de las autoridades literarias. Si solo la vemos desde un formalismo, desde un mayor grado de "artepurismo", no podremos entender bien las revoluciones estéticas de cada tradición literaria. La novela de la violencia fue una revolución estética en Colombia porque transformó la manera de enunciar y de representar la realidad en la literatura. Los testimonios de la época afirman que este tipo de novela vendió mucho, y eso podría indicar, a simple vista, que pertenecía al campo heterónomo, al de la gran producción, pero nuestro mercado editorial era muy pequeño, lo que hizo este tipo de novela, en una sociedad en donde la institucionalización de las prácticas literarias era precaria, fue ampliar ese público, es decir, ayudó a aumentar el grado de autonomía institucional del campo literario. 
Si bien desde finales del siglo XIX, sobre todo, gracias a los trabajos críticos de Baldomero Sanín Cano, y luego con los Nuevos, se empezó a propender por la libertad artística. Lo cierto es que la política fue parte fundamental de la vida literaria colombiana. Los escritores se asumieron en un compromiso político que no les impidió, sino que, por el contrario, animó sus búsquedas de un arte autónomo para poder decir lo que quisieran y hacer las obras que quisieran, es decir, convirtieron los motivos extraestéticos en estéticos. Lo mismo hicieron, a su modo, los escritores latinoamericanos de los años sesenta, cuya toma de posición sintetizó muy bien Idelver Avelar (2000) en la expresión "estetización de la política". De ello se deriva que, para los novelistas, se impusiera la tarea - más difícil para los poetas- de incluir la realidad de una manera crítica en las obras literarias. En las primeras décadas del siglo XX, veremos que aquello desembocó en la novela social (José Antonio Osorio Lizarazo, César Uribe Piedrahita, Eduardo Caballero Calderón, y otros) luego en la novela de la violencia y finalmente en la novela de los dictadores latinoamericanos.

-Para mí, los debates en torno al arte comprometido y a la literatura pura tienen que ser revisados en nuestro medio, y tu investigación constituye un paso significativo para hacerlo, tal como queda demostrado en los puntos que has tocado hasta el momento en esta entrevista. El credo del arte por el arte es, sin duda alguna, un efecto postural, una forma que el escritor de mediados del siglo XX en Francia encontró para legitimar y valorizar una posición social e institucional que le era intolerable: la de su marginalización social y económica en el sistema burgués. Se trataba, pues, de una manera de hacer de la necesidad una virtud, para retomar la expresión de Bourdieu, de valorizar los márgenes. La rarificación del producto como una forma de distinción y de afirmación de su singularidad no es más que el resultado de esta postura. Total, no existe un "arte puro" como algo en sí mismo, sino como credo que rige las representaciones valorizantes del autor y de la literatura, un credo que no es para nada desinteresado.

-Efectivamente, y también en el campo literario colombiano y en Latinoamérica. Julio Ramos (1989) hizo una investigación en donde demostró que en Latinoamérica no podemos hablar de una estética pura o de un "artepurismo" por las condiciones materiales, económicas, sociales y políticas del continente, ni mucho menos en Colombia, sobre todo por lo que he tratado de contar, y es la importancia que tiene la política dentro del campo literario. Lo que tú planteas demostraría, entonces, que los casos colombiano y latinoamericano no representarían una excepción, sino que se enmarcan en la generalidad del funcionamiento de la historia literaria occidental.

Lo anterior sintetiza muy bien la toma de posición de Jorge Zalamea Borda en $E l$ gran Burundún Burundá ha muerto. Él hizo una literatura que es altamente simbólica —autónoma en términos estéticos-y a la vez comprometida políticamente. Son las 
dos cosas al mismo tiempo y logró esa síntesis a mediados del siglo XX. ¿Cómo lo hace? Gracias a la acumulación histórica de capital simbólico, derivada de las luchas ganadas por los escritores para acrecentar el grado de autonomía ideológica que se requiere para el funcionamiento del campo intelectual (luchas a las que él contribuyó activamente y por las que tuvo que elegir el autoexilio). Esta acumulación permitió que, en el momento de producción de la obra de Jorge Zalamea, las rupturas estéticas pudieran conjugarse con las ideológicas.

Pregunta del público: ¿En algún momento de la investigación lidiaste con la pregunta de si la teoría de los campos era la adecuada? ¿No hay otros marcos teóricos más adecuados para investigar la literatura colombiana o incluso latinoamericana?

Marín: La teoría de Bourdieu es una teoría que está muy bien formulada y que en Colombia no ha sido bien asumida - tan solo trabajada tangencialmente- e incluso diría que ha sido bastante despreciada, porque a los críticos literarios colombianos no nos gusta mucho la perspectiva de la sociología de la literatura, sino que nos gusta "interpretar" las obras desde una perspectiva absolutamente temática y esencialista. Ese tipo de trabajos estarían bien, si no fueran la mayoría - y ahora con los Estudios Culturales han aumentado-. Me gusta la sociología de la literatura que proponen Bourdieu y sus seguidores - incluso sus críticos - , porque muestran la cara menos "linda", menos sublime de la literatura: lo "sucio" de hablar de economía, de materialidad, de soportes, de mediadores, de "roscas", de que muchos son los invitados, pero realmente muy pocos los que llegan a tener una posición reconocida dentro del campo literario, de los autores que no tienen nada de desinteresado cuando escriben, de la lucha por la monopolización de la definición legítima de la literatura. Indagar por ese lado "oscuro" nos hace mucha falta en Colombia y espero estar contribuyendo a ello con mis trabajos, al igual que lo han hecho el mismo Juan Zapata y el grupo de investigación Colombia: Tradiciones de la Palabra. De allí que, a partir de esta investigación, haya empezado a indagar en los estudios editoriales, que es lo que ahora estoy haciendo.

Elegí a Bourdieu no porque yo tenga un pensamiento colonizado, ni tampoco porque no lea crítica literaria latinoamericana. De hecho, la teoría de los campos la puse siempre en relación con los trabajos que han hecho directamente críticos literarios y culturales argentinos - los que más han estudiado a Bourdieu en Latinoamérica - sobre la teoría de los campos de producción simbólica, sobre todo, con los de Carlos Altamirano y Beatriz Sarlo. De hecho, en 2014 se publicó un libro de Mabel Moraña en Chile, que trabaja la recepción de Bourdieu en Latinoamérica - tengo la fortuna de que allí está citado uno de mis primeros trabajos sobre el campo literario colombiano-, es decir, que hay una tradición latinoamericana que ha trabajado la teoría de Bourdieu críticamente y la conozco bien. 
El concepto de autonomía tal como él lo propone y el concepto de campo, cómo funciona la literatura como un campo — que es la forma en la que realmente entiendo la literatura-, no la veo en otro autor o en otra teoría. Lo que hace una teoría es ofrecernos unas estructuras generales para pensar y entender los fenómenos, así que el investigador ofrece toda su creatividad para abordar su objeto de investigación desde tales estructuras, pero sin tener que limitar su comprensión de la complejidad de todo fenómeno literario. Obviamente, a partir de esta investigación he hallado otros teóricos que critican y complementan lo que propuso Bourdieu (Jacques Dubois, Bernard Lahire, Alain Vaillant, Itamar Even-Zohar, Gisèle Sapiro), pero no hay ninguna teoría hasta ahora - aunque suene muy radical — que supere el modelo de Bourdieu para explicar los fenómenos literarios.

Indudablemente, cuando uno toma una teoría extranjera, es claro que uno tiene que problematizarla y ponerla en diálogo con las características y las estructuras locales. Puedo tener todo el archivo - en este libro hago uso de una gran cantidad de fuentes inéditas para la investigación literaria en Colombia-, pero si no tengo las categorías para organizar, delimitar y problematizar ese archivo, quizás no vaya a encontrar la singularidad de lo que estoy analizando. La teoría me permite hacerle preguntas nuevas al archivo o al corpus, incluso dar respuestas inéditas a preguntas que ya se habían hecho.

Entiendo la preocupación porque es mía también. La conclusión acerca de que en Colombia (y ahora ya sabemos también que en ninguna tradición literaria, al menos occidental) no podemos hablar de un "artepurismo", porque la autonomía estética va de la mano de la intelectual (y menos de la institucional por nuestras precariedades económicas y por el descuido de nuestras entidades gubernamentales frente a lo cultural y artístico), es un hecho que define nuestra tradición literaria y su particularidad. Realmente, lo que me permitió la teoría de los campos fue encontrar la singularidad de la tradición literaria colombiana, y eso se lo agradezco a Bourdieu.

Pregunta del público: ¿Qué papel juegan en la autonomía institucional, dentro de la investigación, las editoriales que aún están ligadas al gobierno, que además, popularizan el libro con tirajes muy grandes y baratos?

Marín: Cuando analizamos el mercado editorial y la literatura en relación con la edición, hay que tener en cuenta el tipo de editorial. Tenemos algunas editoriales que se denominan independientes; otras, como corporativas o más comerciales; y las demás, como editoriales institucionales. Dentro de esas editoriales institucionales tenemos las estatales. Las institucionales reciben subvención para funcionar, es decir, no arriesgan ningún dinero cuando publican, sin importar el tiraje que 
publiquen. Entonces, el hecho de ganar o no dinero con lo que se publica determina las formas de difusión y de recepción de lo que se publica, para el caso de nosotros, lo literario.

Para volver a mi investigación, voy a nombrar solamente el caso de Cuatro años a borde de mí mismo. Esta novela vendió 18 ejemplares en el momento de su publicación. Voy a hacer una digresión: a mí me sorprendío mucho el hecho de que nuestros trabajos de investigación literaria estuvieran basados en libros que sólo habían vendido 18 ejemplares y que despreciáramos como objetos de investigación libros que habían vendido, en la misma época, 3000 y hasta 6000 ejemplares, como el caso de las novelas de Arturo Suárez, que es el escritor con el que terminé mi investigación. Me sorprendía mucho cómo este libro que leyeron 18 personas pasó con el tiempo a convertirse en una novela del canon de la literatura colombiana y que el otro lo hubiéramos olvidado, pese a su importancia para la construcción de público lector. Obviamente, en ese caso ocurrió que quienes lo leyeron hicieron reseñas en la prensa, porque eran los que hacían parte de la élite letrada del momento y eran los que escribían para los periódicos importantes del momento. Esa élite letrada era también la que escribía los libros de historia literaria.

Arturo Suárez no aparece en las historias de la literatura, ni aparece en la prensa que revisé para mi investigación. Es como si lo hubieran vetado y, efectivamente, cuando hice la investigación sobre él, me di cuenta de que fue así: lo censuraron porque vendía mucho y su literatura era, según los críticos, "populista". Entonces, el aspecto editorial influye en cómo recibimos un producto literario. La editorial que publicó la novela de Eduardo Zalamea es una editorial que era de Juan Lozano y Lozano - es decir, un intelectual, político, periodista y poeta, muy influyente en el campo intelectual de la primera mitad del siglo XX en Colombia-. Lozano no necesitaba ganar plata con la editorial. Solo hizo su colección y publicó la novela. Así que sus contactos y los del mismo Zalamea, como sus capitales sociales y culturales hicieron lo demás (además de la obra literaria, que se defendía por sí misma). Pero Arturo Suárez escribía otro tipo de literatura para otro tipo de lectores, así que su circuito editorial y su cúmulo de capital simbólico eran distintos. Suárez escribió lo que hoy denominamos novela sentimental. A él lo buscaban los editores, no solamente colombianos, sino también latinoamericanos, para publicar sus novelas en tirajes que se vendían y que se reeditaban. Entonces, es muy importante entender las lógicas de edición y, sobre todo, entender que mantener un equilibrio entre estos distintos tipos de circulación editorial y de editoriales no solo es necesario para el sostenimiento material de la literatura, sino también para el aumento de su autonomía institucional, estética e intelectual. 
Es muy interesante la pregunta porque apunta hacia otra paradoja de la autonomía literaria: si el mercado editorial solo se orientara a ganar grandes sumas de dinero con la literatura, esta moriría, pero si solo se publicara con subvenciones de instituciones o del gobierno, también. La autonomía institucional tiene como objetivo separar al escritor de campos distintos al literario, pero lo que acabé de decir demuestra que el Estado debe seguir interviniendo - como lo hace muy bien con los bancos para "salvarlos" - en materia de cultura, para ayudar a aumentar o a mantener la autonomía institucional del campo artístico, para no dejar la literatura completamente en manos del mercado, aunque ello implique — una paradoja más — que el campo político incida en las decisiones de lo que se canoniza; se trata — en una situación ideal - de que el Estado respete, tanto como sea posible, las luchas ganadas por los escritores en materia de autonomía intelectual y estética. El último caso que he investigado y que tiene que ver directamente con las editoriales estatales ilustra muy bien lo que acabo de decir: son las colecciones de Colcultura entre 1975 y 1982, en las que aparecieron, entre otras, la primera edición Que viva la música y la primera edición de Estaba la pájara pinta sentada en el verde limón.

Colcultura es muy importante como editorial estatal $-\mathrm{y}$ en general, institucional-, porque publica trabajos que no son publicados por otras editoriales que necesitan ganar plata y, además, porque al sacar ediciones "populares" o económicas posibilitan el aumento del público lector y del grado de profesionalización del escritor con el pago de derechos de autor, los cuales también son elementos importantes de la autonomía institucional. Eso mismo lo habían hecho dos colecciones editoriales estatales anteriores en la primera mitad del siglo XX: la Biblioteca Aldeana, en los años treinta; y la Biblioteca Popular de Cultura Colombiana, en los años cuarenta. Hice el estudio de las colecciones de Colcultura acerca de cuántas primeras ediciones había y cuántas de esas primeras ediciones no se han vuelto a publicar, y es entre el $70 \%$ y el $80 \%$ de cada una de las colecciones. Esto quiere decir que son textos y compilaciones que se habrían perdido para siempre si no las hubiera publicado Colcultura, y que hoy por hoy son nuestros clásicos de la literatura y de la filosofía colombianas del siglo XX. Una de las funciones de la edición estatal es esa: como no tiene que ganar dinero, entonces puede apostarle a obras del campo de la producción restringida —el más autónomo - que no tienen acceso fácil a otros circuitos de difusión, y eso aumenta la autonomía de ese subcampo, y en general, de la autonomía estética e institucional — lo mismo hacen, a su manera, aunque sí arriesgando plata, las editoriales "independientes"-.

Por supuesto, hay casos dentro de la edición institucional que demuestran que los criterios de selección de lo publicado no son tan autónomos como uno quisiera; por ejemplo, el amigo de Gloria Zea — directora de Colcultura durante el período 
que investigué - le pidió el favor de publicarle un libro y Zea, por afecto, lo hizo, o el caso del político que le hizo la misma petición para un amigo o para él mismo, y debía hacerlo, porque si no, no le daban más presupuesto para Colcultura el año siguiente. En fin, hay que mirar bien el funcionamiento de cada editorial, especialmente el proceso de publicación y de difusión en cada una. En últimas, lo que demuestra lo anterior es que — como dije al inicio — la autonomía siempre es relativa y por eso hay que seguir luchando para aumentar su grado o bien para que los espacios de su defensa no se disminuyan.

\section{Referencias bibliográficas}

1. Avelar, Idelver. (2000). Alegorías de la derrota: la ficción postdictatorial y el trabajo delduelo. En línea.

2. Marín Colorado, Paula Andrea.(2017). Novela, autonomía literaria y profesinalización del escritor en Colombia (1926-1970). Medellín: Universidad de Antioquia-La Carreta Editores.

3. Moraña, Mabel. (2014). Bourdieu en la periferia: capital simbólico y campo cultural en América Latina. Chile: Cuarto Propio.

4. Ramos, Julio. (1989). Desencuentros de la modernidad en América Latina. Literatura y política en el siglo XIX. México: Fondo de Cultura Económica.

5. Sarlo, Beatriz. (1988). Una modernidad periférica. Buenos Aires 1920 y 1930. Buenos Aires: Nueva Visión. 